\title{
Management of Tibial Metaphyseal Fractures by Hybrid External Fixator
}

\author{
S. K. Venkatesh Gupta, Gottipati Sunil \\ Department of Orthopaedics, Mamata General Hospital, Khammam, India \\ Email: doctororthopaedics@gmail.com
}

Received 10 February 2014; revised 12 March 2014; accepted 19 March 2014

Copyright (C) 2014 by authors and Scientific Research Publishing Inc.

This work is licensed under the Creative Commons Attribution International License (CC BY). http://creativecommons.org/licenses/by/4.0/

c) (i) Open Access

\begin{abstract}
Introduction: The Hybrid External Fixator combines the advantages of the monolateral pin fixators and the circular Ilizarov wire fixators. Principle of early motion has been touted as the functional savior of major intra articular injuries in application of hybrid external fixation. Materials \& Methodology: 48 patients were considered for the study with tibial fractures admitted in Mamata General Hospital from May 2011 to May 2013. Results: The union and functional outcome of hybrid external fixator in simple and complex proximal and distal metaphyseal fractures of tibia in adults was evaluated at our centre. The fractures of the proximal tibia united with an average of 13.3 weeks (12 - 16 weeks). The fractures of the distal tibia united with an average of 14.42 weeks (13 - 22 weeks) with minimal complications. Conclusion: Our study shows high satisfaction rate after fixation, provides adequate stability and allows early motion of the joint. It is also effective in extra articular fractures occurring within $5 \mathrm{~cm}$ of the joint as the IM nails often do not provide enough stability and plating requires extensive soft tissue dissection.
\end{abstract}

\section{Keywords}

Hybrid External Fixator; Tibial Metapyseal Fractures

\section{Introduction}

Intra-articular and extra-articular fractures of the proximal and distal tibia present a wide spectrum of soft tissue and bony injury patterns that can produce permanent impairments [1] [2]. For patients treated operatively, the residual disabilities are not only attributable to the severity of the injury, but also to the complications and side effects of the operative intervention. The low energy type of fractures often gets dramatic results with open reduction and internal fixation. But high energy fractures are documented to show a high amount of complications due to soft tissue coverage, skin necrosis, infections and also the usually comminuted nature of the fractures. 
Underlying soft tissue injury, compound wounds are challenging conditions in management of proximal and distal metaphyseal fractures of tibia. To overcome the same, there was a need for less cumbersome, yet more rigid external fixation modality that can maintain fracture alignment and promote soft tissue healing. There was a drastic change from a simple uniplanar frame to more complex circular frames [3]-[6]. The Hybrid External Fixator combines the advantages of the monolateral pin fixators and the Ilizarov ring fixators. The tensioned wires provide improved fixation in the cancellous fragment, whereas the pin fixators give adequate stability to the diaphyseal fragment. It is simple, has a rapid and straight forward application, reduces surgical time and is minimally invasive. It is adjustable. Hence fracture reduction can be easily attained after frame assembly [7]. Along with rigid fixation, it allows immediate mobilization of the joints and early weight bearing [8]. The goal of operative treatment is to obtain anatomic realignment of the joint surface while providing enough stability to allow early motion [9]. This should be accomplished using techniques that minimize osseous and soft tissue devascularization in the hopes of decreasing the complications resulting from treatment [10]. In this study we would like to assess the role of hybrid external fixation of intra and extra articular fractures of proximal and distal tibia.

\section{Material and Methods}

Between May 2011 and May 2013, 48 patients with complex tibial metaphyseal injuries were admitted to our institution. 23 patients with proximal tibial fractures (18 closed and 5 compound) and 25 patients having distal tibial fractures (13 closed and 12 compound) were included in the study. Patients with ipsilateral femur fractures and intraarticular fractures with severe comminution were excluded (Type C3 AO/OTA Classification) [11] from the study.

All the patients were explained and motivated about the cosmetic issues and difficulties in daily routines by the application of a hybrid external fixator.

\subsection{Instruments and Implants (Figures $1(a)$ and (b))}

- Ilizarov half rings, $5 / 8$ rings.

- Bayonet edged Ilizarov wires-plain/olive wires (Olive wires have small beads called "olives". Wire tension can pull the olive against a bone fragment, and thus these wires when inserted and tensioned in opposite directions can produce interfragmentary compression) [12].

- Slotted/cannulated wire connecting bolts.

- Twisted connecting plates.

- $4.5 \mathrm{~mm}$ Schanz pins.

- Pin clamps.

- Connecting rods.

- Nuts and Bolts.

- $3.5 \mathrm{~mm}$ drill bits.

- T-handle.

- 10/11 wrenches.

- Dynamometric Tensioner.

- Wire bender/cutter.

\subsection{Operative Procedure [13]-[17]}

Position-supine with affected leg elevated on a pillow/sand bag for distal end fractures and with a pillow under the distal thigh for proximal end fractures. Compound wounds are thoroughly debrided.

Securing articular fragments: After reduction of the peri-articular fragment, it was secured using three Ilizarov wires. The wires (bayonet tipped or trocar tipped wires) were pushed manually until it hit the cortex, then drilled across both the cortices and hammered out through the opposite soft tissue. Nerves and vessels were avoided based on the safe corridor for pin insertion in the leg. Olive wires were used in cases where compression of the longitudinal split is needed. The first wire was passed parallel to the joint in a lateral to medial direction under fluoroscopic control. It is fixed to an appropriate size ilizarov $3 / 4$ ring so as to leave at least $2 \mathrm{cms}$ 
between the leg and the ring on all sides. One wire each from posterolateral to anteromedial and posteromedial to anterolateral under fluoroscopic control keeping an angle of 30 to 60 degrees between the wires. The axial plane of the wires was about $5 \mathrm{~mm}$ from the joint and as parallel to it as possible. If any internal fixation using cancellous screws was deemed necessary it was done before passage of the wires. The wires were fixed to the rings using slotted wire connecting bolts and tensioned using a dynamometric tensioner. Skin traction by the wires, if any were released using minimal incisions on the side of the skin stretching.

Securing the diaphyseal fragment: Three $4.5 \mathrm{~mm}$ Shanz pins were placed $3-4 \mathrm{~cm}$ apart on the anteromedial surface of tibia perpendicular to its longitudinal axis. All the pins were placed in the same sagittal plane. The pins were connected to the connecting rods with the pin clamps.

Fracture reduction and frame assembly (Figures 2-5): Fracture reduction was obtained using longitudinal traction (Ligamentotaxis) under the image intensifier. The pin fixator assembly was connected to the ring assembly using a connecting clamp. All nuts and bolts were tightened. One or two connecting rods were connected diagonally from the Shanz pins to ring frame for extra stability. The compound fractures were treated with primary or secondary flap reconstructions or split thickness skin grafting after healing of the wound.

Follow up: Patients are followed every month until 6 months and thereafter quarter yearly until 2 years, for radiological union and functional outcome assessment. Functional outcome was assessed using IOWA knee and Ankle scores.

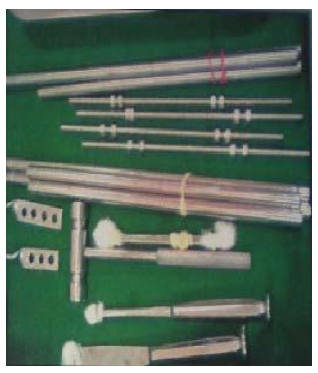

(a)

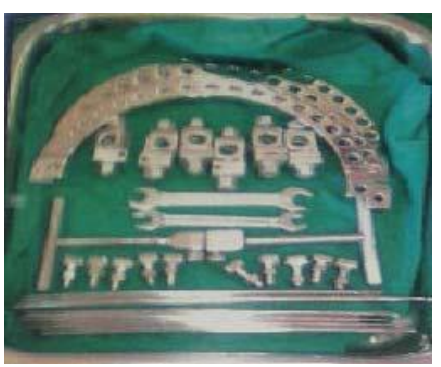

(b)

Figure 1. Instruments and implants.

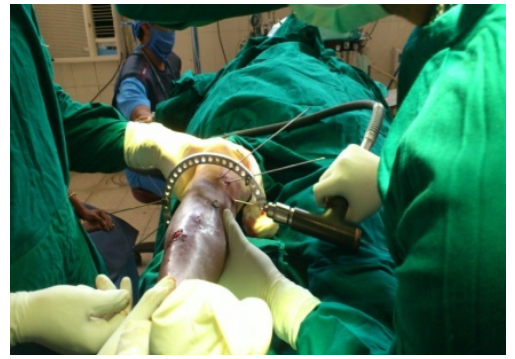

(a)

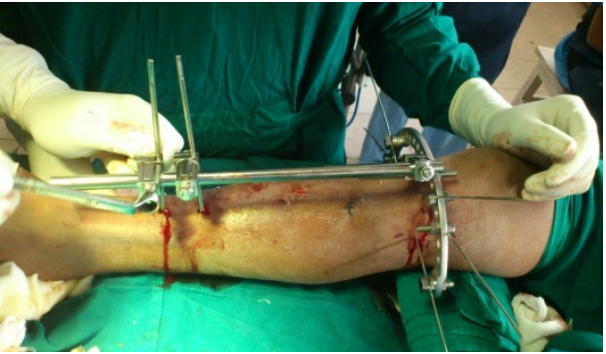

(b)

Figure 2. Tibial plateau fracture: Intra operative procedure.

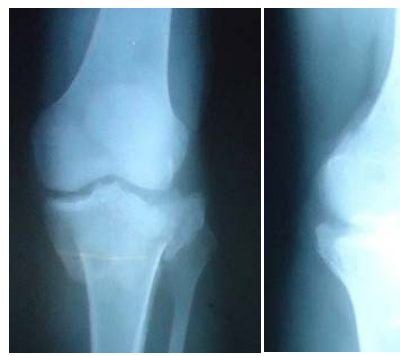

(a)

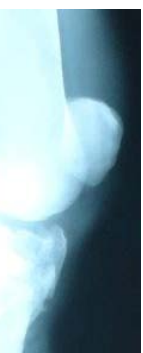

Figure 3. Tibial plateau fracture: Pre and Post operative X-ray.

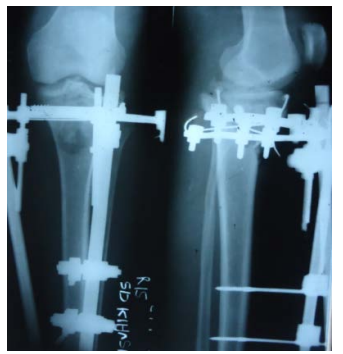

(b) 


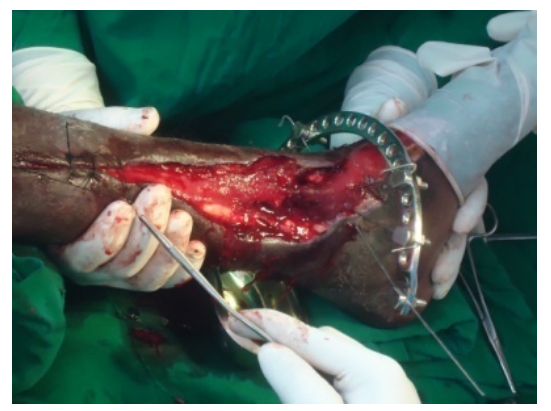

(a)

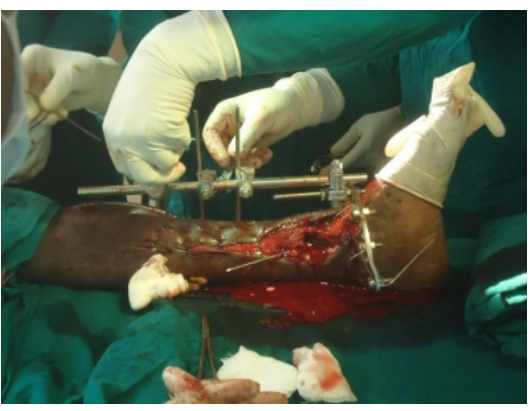

(b)

Figure 4. Distal end tibial fracture: Intra operative.

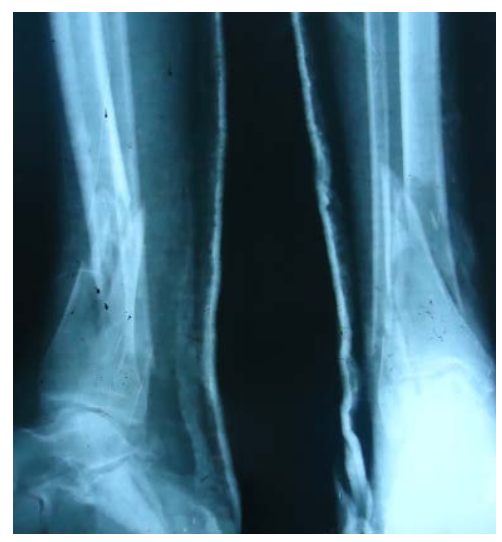

(a)

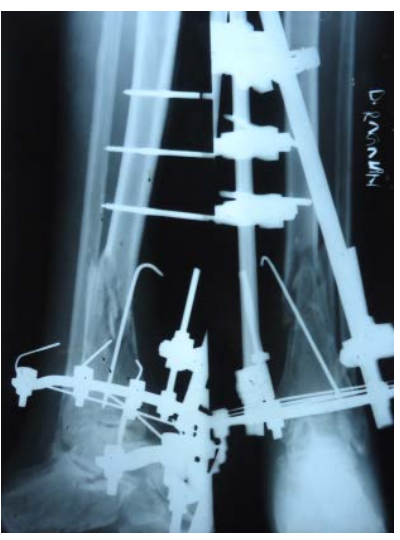

(b)

Figure 5. Distal end tibial fracture: Pre and post operative X-ray.

\section{Results}

48 cases were included of which $32(67 \%)$ were males and $16(33 \%)$ were females. Average age of the patients was 40.2 years with age range between 22 - 61 years. Out of the 48 cases, 31 (65\%) cases were closed fractures and 17 (35\%) cases were compound fractures. 23 patients had proximal tibial fractures (18 closed and 5 compound) and 25 patients had distal tibial fractures (13 closed and 12 compound) (Figure 6).

One case of proximal tibial fracture with coronal plane extension was fixed with mini open percutaneous cannulated cancellous screw fixation in anterio-posterior plane. In distal tibial group, fibular fractures were fixed with $1 / 3^{\text {rd }}$ semi tubular plating among 6 cases and with rush nailing in 9 cases.

The fractures of the proximal tibia united with an average of $\mathbf{1 3 . 3}$ weeks (12 - 16 weeks). The fractures of the distal tibia united with an average of $\mathbf{1 4 . 4 2}$ weeks (13 - 22 weeks). There were two cases of delayed union in proximal tibial fractures, which united with bone marrow injections. There was only one case of non-union that later required bone grafting. There were two cases of delayed union and no cases of non-union in distal tibial metaphyseal fixation. 8 cases of distal tibial group and 5 cases of proximal tibial group developed pin tract infections, that healed with short course of appropriate antibiotics and daily antiseptic dressings. We had 12 (48\%) cases of ankle stiffness in distal tibia group and three cases of knee stiffness in proximal tibial group. There was one case of failure of hardware in proximal tibial group, where in external fixator device was removed and ORIF with LCP plating and bone grafting was done. One case of distal tibial fixation went in to valgus malunion, probably due to unattended lower third fibular fracture (Figure 7). Implant removal was done as the bone consolidates at an average of 6.4 months in this series (4 - 9 months) followed by patellar tendon bearing cast application. In one case of distal tibia fracture, transposition rotation flap was done over the compound wound after no signs of infection and in 4 cases of proximal tibial group and 5 cases of distal tibial group split skin grafting was done.

The fair results in both the groups were mainly due to the knee or ankle stiffness and delayed union (Figure 
8). One case of poor outcome in proximal tibial group was due to hardware failure. There was no significant difference in rates of union, healing, functional outcome and number of complications among both proximal tibial and distal tibial groups, suggesting that it can be effectively used in either scenarios.

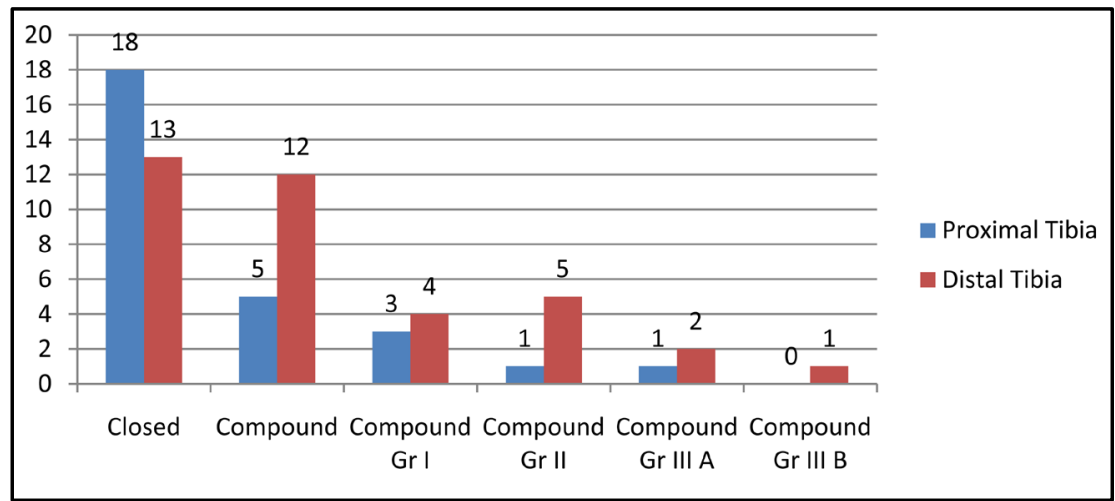

Figure 6. Distribution of proximal tibial and distal tibial fractures.

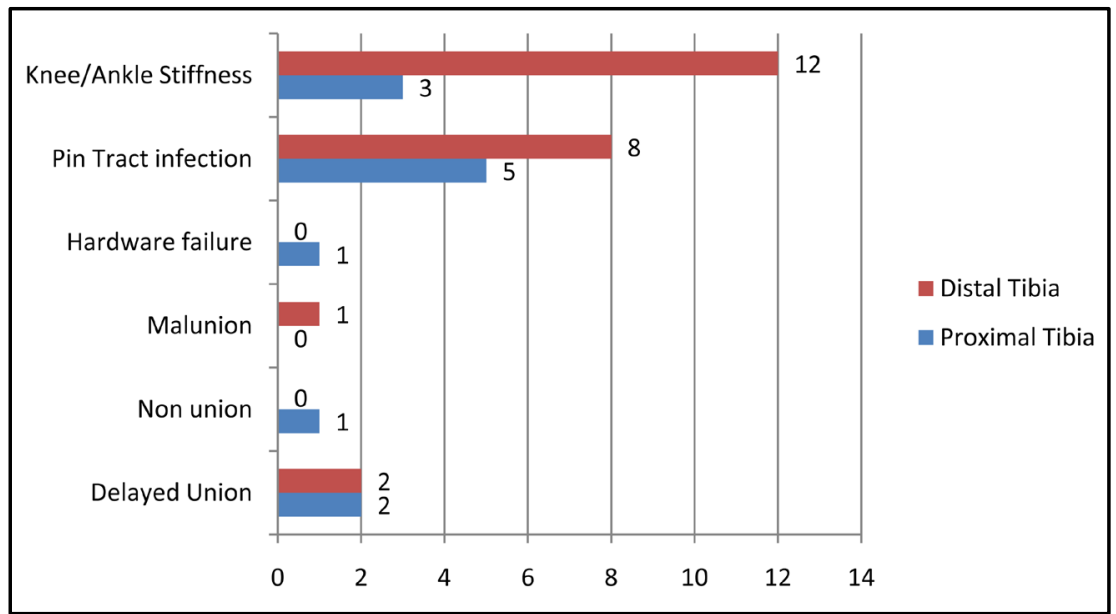

Figure 7. Complications of hybrid external fixation: Proximal vs distal tibial fixation.

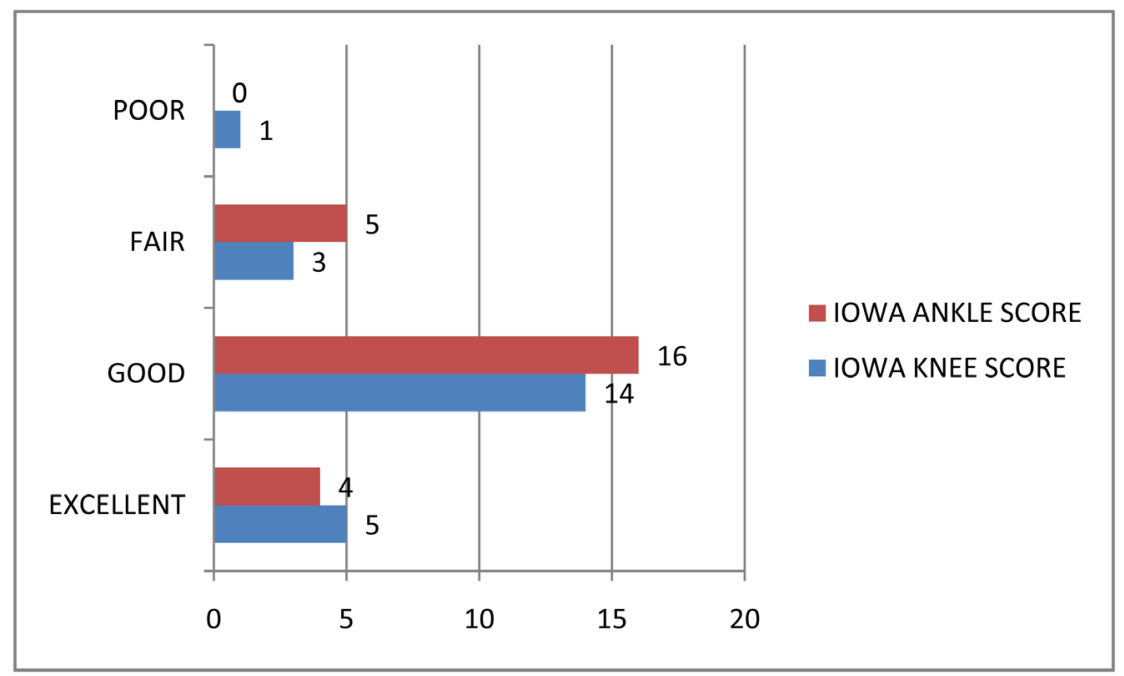

Figure 8. Functional outcome. 


\section{Conclusion and Recommendations}

This method provides adequate stability and allows early motion for both proximal and distal tibial fractures. The closed reduction not only helps achieve reduction in difficult situations, but also in rapid union, as it preserves blood supply to the fragment. This method limits further damage to the already compromised soft tissue where wounds can be left open. It is also effective in extra articular fractures occurring within $5 \mathrm{~cm}$ of the knee joint proximally and $3-4 \mathrm{~cm}$ from the ankle joint distally, wherein the IM nails often do not provide enough stability and plating requires extensive soft tissue dissection. It can also be used in osteoporotic and unreconstructable comminuted metaphyseal fractures with poor bone stock. We recommend that hybrid external fixators for both proximal and distal tibial metaphyseal fracture fixation where in soft tissue injury and compound wound are the major constraints for internal fixation.

\section{References}

[1] Salter, R.B. and Ogilvie-Harris, D.J. (1979) Healing of Intra-Articular Fractures with Continuous Passive Motion. AAOS Instructional Course Lectures, 28, 102-117.

[2] Sirkin, M. and Sanders, R. (2001) The Treatment of Pilon Fractures. Clinical Orthopaedics, 32, 91-102.

[3] French, B. and Tornetta, P. (2000) Hybrid External Fixation of Tibial Pilon Fractures. Foot and Ankle Clinics, 5, 2000.

[4] Apley, A.G. (1979) Fractures of the Tibial Plateau. Orthopedic Clinics of North America, 10, 61-74.

[5] Schatzker, J., McBroom, R. and Bruce, D. (1979) The Tibial Plateau Fracture: The Torontoexperience (1968-1975). Clinical Orthopaedics, 138, 94-104.

[6] Schatzker, J. (1988) Fractures of the Tibial Plateau. In: Schatzker, J. and Tile, M. (1988) The Rationale of Operative Orthopaedic Care, Springer-Verlag, New York, 279-295.

[7] Yang, L., Saleh, M. and Nayagam (2000) The Effect of Different Wire and Screw Combinations on the Stiffness of Hybrid External Fixator. Proceedings of the Institution of Mechanical Engineers, 214, 669-676. http://dx.doi.org/10.1243/0954411001535697

[8] Mallik, A.R., Covall, D.J. and Whitelaw, G.P. (1992) Internal versus External Fixation of Bicondylar Tibial Plateau Fractures. Orthopedic Reviews, 21, 1433-1436.

[9] Young, M.J. and Barrack, R.L. (1994) Complications of Internal Fixation of Tibial Plateau Fractures. Orthopedic Reviews, 23, 149-154.

[10] Dillin, L. and Slabaugh, P. (1986) Delayed Wound Healing, Infection, and Non Union Following Open Reduction and Internal Fixation of Tibial Plafond Fractures. Journal of Trauma, 26, 1116-1119. http://dx.doi.org/10.1097/00005373-198612000-00011

[11] Helfet, D.L., Koval, K., Pappas, J., Sanders, R.W. and Dipasquale, T. (1994) Intraarticular "Pilon” Fracture of the Tibia. Clinical Orthopaedics, 298, 221-228.

[12] Barbieri, R., Scbenk, R., Koval, K., Aurori, K. and Aurori, B. (1996) Hybrid External Fixation in the Treatment of Tibial Plafond Fractures. Clinical Orthopaedics, 332, 16-22. http://dx.doi.org/10.1097/00003086-199611000-00004

[13] Gaudinez, R.F. and Mallikar, S.M. (1996) Hybrid External Fixation in Tibial Plafond Fractures. Clinical Orthopaedics, 329, 223-232. http://dx.doi.org/10.1097/00003086-199608000-00028

[14] Anglen, J.O. (1999) Early Outcome of Hybrid External Fixator for the Fractures of Distal Tibia. Journal of Orthopaedic Trauma, 13, 92-97. http://dx.doi.org/10.1097/00005131-199902000-00004

[15] Yang, M., Nayagam, S. and Saleh, M. (2003) Stiffness Characteristics and Interfragmentary Displacement with Different Hybrid External Fixators. Clinical Biomechanics (Bristol, Avon), 18, 166-172. http://dx.doi.org/10.1016/S0268-0033(02)00175-4

[16] Piper, K.J., Won, H.Y. and Ellis, A.M. (2005) Hybrid External Fixation in Complex Tibial Plateau and Plafond Fractures: An Australian Audit of Outcome. Injury, 36, 178-184.

[17] Aggarwal, A.K. and Nagi, O.N. (2006) Hybrid External Fixation in Periarticular Tibial Fractures. Good Final Outcome in 56 Patients. Acta Orthopaedica Belgica, 72, 434-440. 